\title{
Evidence-based Review of the Bioenterics Intragastric Balloon for Weight Loss
}

\author{
Jean-Marc Dumonceau
}

Received: 30 April 2008 / Accepted: 23 May 2008 /Published online: 21 June 2008

(C) Springer Science + Business Media, LLC 2008

\begin{abstract}
We reviewed clinical studies performed with the Bioenterics intragastric balloon (BIB) to promote weight loss. Thirty studies were included $[18$ prospective (5 randomized), 12 retrospective], totaling 4,877 patients. Only one of three sham-controlled trials found a significantly higher weight loss with the BIB vs the sham procedure plus exhaustive follow-up. In nonrandomized studies, weight loss with the BIB averaged $17.8 \mathrm{~kg}$ (range, 4.9-28.5), corresponding to BMI changes of $4.0-9.0 \mathrm{~kg} / \mathrm{m}^{2}$. Comorbidities resolved or improved in $52-100 \%$ of patients. Best short-term results were observed in patients devoid of binge eating disorder with a BMI in the $30.0-40.0 \mathrm{~kg} / \mathrm{m}^{2}$ range; the $\mathrm{BIB}$ also helped to prepare superobese patients for bariatric surgery. Severe complications were exceptional (gastric perforation and intestinal obstruction; $0.2 \%$ each); digestive intolerance prompted early BIB removal in $2.5 \%$ of patients. Long-term ( $\geq 2$ years) results are awaited, as well as well-designed studies to define the best indications for this therapy.
\end{abstract}

Keywords Obesity · Gastrointestinal endoscopy ·

Gastric balloon $\cdot$ Weight loss

Abbreviations
BMI body mass index
BIB Bioenterics intragastric balloon

Conflict of interest: none

J.-M. Dumonceau $(\bowtie)$

Division of Gastroenterology and Hepatology,

Geneva University Hospitals,

Micheli-du-Crest Street, 24,

1205 Geneva, Switzerland

e-mail: Jean-Marc.Dumonceau@hcuge.ch

\section{Introduction}

Intragastric balloons were proposed as an aid to promote weight loss more than 20 years ago, but original models were rapidly abandoned because they were ineffective and potentially harmful. In 1987, an expert meeting was held to define the requirements for an "ideal" intragastric balloon and the settings of a weight loss program using this technique [1]. Since then, three models of intragastric balloon have been made commercially available: the first one [Bioenterics intragastric balloon (BIB)] was filled with liquid and it has been implanted in tens of thousands of patients; two different, air-filled, models (Heliosphere Bag and Endogast) have recently become available. The Endogast presents the particularity of requiring a combined endoscopic and surgical insertion procedure (an inflation/ deflation port is attached to the balloon and implanted subcutaneously).

Here, we review the experience published about the liquid-filled BIB used as an adjunct for weight loss promotion in humans; readers interested in air-filled balloons are referred to the few recent articles published about these devices [2-4].

\section{Methods}

A review of the literature was performed by searching PubMed for the period from January 1995 to February 2008 , with the search terms intragastric and balloon. A total of 157 studies were found, of which 127 studies were excluded because they did not assess weight loss in humans $(n=82)$, included $\leq 15$ patients $(n=20)$, contained no original data $(n=9)$, were not available in the English language $(n=7)$, contained no abstract $(n=6)$, or used a 
balloon different from the BIB $(n=3)$. This resulted in a total of 30 studies to be included in this review [5-34].

\section{Practical Considerations}

Treatment with the BIB should be proposed in the setting of a multidisciplinary team, after failure of conservative measures and exclusion of a hormonal or genetic cause for obesity. Candidates for this treatment must understand that the BIB is a temporary aid to promote weight loss. Indications retained for BIB therapy are generally based on criteria of body mass index (BMI) and the presence or absence of comorbidities, but these criteria vary between studies. Compared to recommendations for bariatric surgery and weight-loss drugs released by the US National Health Institutes [35], criteria used for BIB therapy generally correspond to a disease severity that is intermediate between those stated for these two therapeutic options. Commonly cited criteria for BIB therapy include a BMI comprised (in kilograms per square meter) between (1) 27.0 and 29.9, in association with severe comorbidities that will likely improve with weight loss (typically insulin-requiring diabetes); (2) 30.0 and 34.9, with comorbidities; (3) 35.0 and 39.9 without comorbidities; (4) or $\geq 40$, mostly as a preparation for bariatric surgery. Contraindications are listed in Table 1.

Balloon insertion and removal are performed under conscious sedation or general anesthesia. Briefly, (1) upper gastrointestinal endoscopy is performed to detect possible contraindications to BIB insertion; (2) immediately after endoscope removal, the BIB placement assembly is inserted through the mouth into the stomach (if the procedure is performed under conscious sedation, asking the patient to

Table 1 Contraindications generally cited to the placement of Bioenterics intragastric balloon

\section{Contraindications}

Absolute contraindications
Previous gastric surgery
Hiatal hernia $\geq 5 \mathrm{~cm}$
Coagulation disorder
Potentially bleeding lesion of the upper gastrointestinal tract
Pregnancy or desire to become pregnant, breast-feeding
Alcoholism or drug addiction
Severe liver disease
Any contra-indication to endoscopy
Relative contraindications
Previous abdominal surgery
Hiatal hernia, esophagitis
Crohn's disease
Intake of nonsteroidal anti-inflammatory drugs
Psychiatric disorders

swallow may facilitate catheter's progression or, if it is performed under general anesthesia with tracheal intubation, temporary deflation of the tracheal balloon may be helpful); (3) the balloon is positioned in the fundus under endoscopic control, the chuck is removed from the insertion catheter, and the balloon is inflated by injecting saline mixed with $10-\mathrm{ml}$ methylene blue into the catheter; (4) finally, once the desired volume has been injected, the balloon is released by a short pull on the catheter. The BIB should be removed after a maximum of 6 months because beyond this period, the risk of spontaneous balloon deflation significantly increases.

Early complications include epigastric pain and nausea that develop in a majority of patients a few hours after BIB insertion. Tropisetron has been shown in a randomized trial to be most effective to reduce the incidence of vomiting during the first $24 \mathrm{~h}$ following BIB insertion [32]. This side-effect has been overlooked in many studies because it is usually transient, but patients should be well aware of this possibility and, if BIB insertion is performed on an ambulatory basis, patients should be instructed to ask for medical advice in case of prolonged symptoms (due to the risk of dehydration). Persistence of these symptoms for $\geq 1$ week has required BIB removal in up to $7 \%$ of cases [12].

Balloon removal requires specific material that should be available as soon as a program of BIB therapy is started [33]. A randomized study has shown that a double-channel endoscope was superior to a single-channel endoscope in terms of number of lost balloons, balloon retrieval duration, and patient discomfort (the BIB was seized with both grasping forceps and a snare) [16]. However, in the present author's experience, the use of dedicated ancillary devices to fully empty and then grasp the balloon consistently allows BIB removal, even with a single-channel endoscope [33]. Nonetheless, a double-channel endoscope may be useful because gastric content may be abundant even if a liquid diet has been prescribed for the $24 \mathrm{~h}$ preceding BIB removal.

\section{Results}

Short-term Weight Loss

Three randomized studies have compared short-term weight loss with the BIB vs a sham procedure. In a study including 32 patients (mean BMI, $43.7 \mathrm{~kg} / \mathrm{m}^{2}$ ) [19], the BMI had significantly decreased 3 months after BIB insertion but not after the sham procedure (Fig. 1). After crossover between groups, the BMI remained almost stable in patients who had the BIB extracted, while it significantly decreased in patients who had received the BIB for the first time. Authors' findings apparently were in contradiction with those of two other trials, which found similar weight losses 


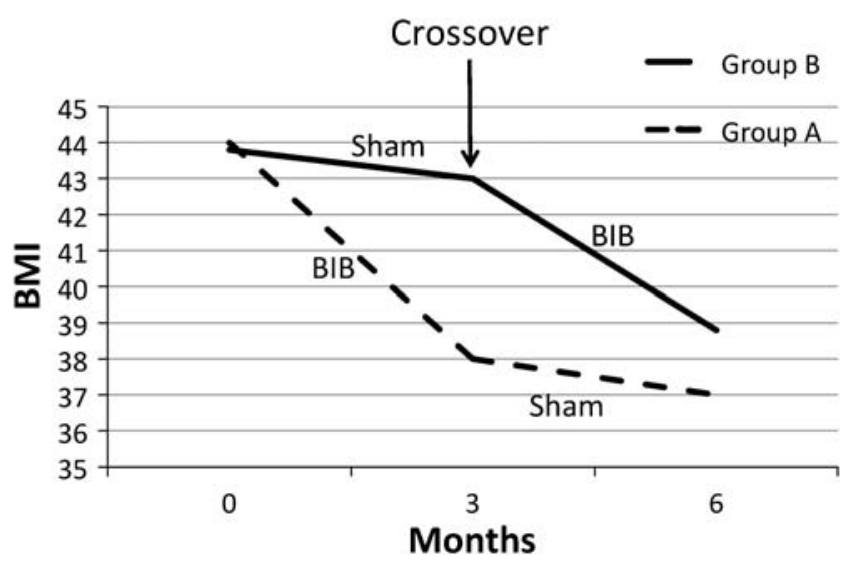

Fig. 1 Evolution of the body mass index $(B M I)$ in patients randomized to Bioenterics intragastric balloon $(B I B)$ insertion or sham procedure, with crossover at 3 months. $P$ values for BMI changes over 3 -month periods were $<0.001$ for each group during BIB therapy and not significant during sham therapy. Adapted from Genco et al. [19] with permission

with the BIB and the sham procedure (1) in 43 patients with a mean BMI of $43.3 \mathrm{~kg} / \mathrm{m}^{2}$ (weight losses, $12.9 \mathrm{vs} 11.2 \mathrm{~kg}$, respectively) [23] and (2) in 21 patients with a mean BMI of $50.4 \mathrm{~kg} / \mathrm{m}^{2}$ (weight losses, $12.7 \mathrm{vs} 8.9 \mathrm{~kg}$, respectively) [22]. The authors estimated that the good results observed with the sham treatment could have been related to the "exhaustive periodic assessment of dietetic habit" [22]. Absolute weight loss was also available in 22 nonrandomized studies included in this review: among 4,371 patients, mean weight loss with the BIB was $17.8 \mathrm{~kg}$ (extremes of the means, 4.9-28.5 kg) [5-13, 15, 17, 18, 20, 21, 25-31, 34].

It is important to inform candidates for BIB insertion that $20-40 \%$ of patients fail to achieve a significant weight loss (often defined as $\geq 10 \%$ baseline weight or $\geq 25 \%$ excess weight) $[20,23,24]$. Such failures may be related to the request of early BIB removal by patients who present a digestive or psychological intolerance to the BIB (103 of 4,361 patients for whom the information was available; $2.4 \%$ ), to the early vanishing of anticipated effects on hunger and early satiety, or to patient's adaptation of food intake. Endoscopic adjustment of the BIB-filling volume has been proposed to palliate these problems [23], but it has been abandoned due to technical difficulties [11].

\section{Evolution of Body Weight Loss at 1 Year} After BIB Removal

Two studies (one randomized, one uncontrolled) totaling 143 patients have reported that, 1 year after BIB removal, patients had regained $41 \%$ and $28 \%$ (mean values, respectively) of the absolute weight loss observed at BIB removal $[20,23]$. Herve et al. also detailed that $56 \%$ of patients had $\geq 20 \%$ excess weight loss 1 year after BIB removal (compared to $74 \%$ at the time of BIB removal), and Mathus-Vliegen et al. detailed that the proportion of patients with $\geq 10 \%$ baseline weight loss had dropped from $75 \%$ to $47 \%$ during the year following BIB removal. A combination of therapies (to induce weight loss in refractory patients and then maintain it) might prove valuable: in a nonrandomized controlled trial [36], a 6-month course of sibutramine after BIB removal allowed limiting weight regain at $1.8 \mathrm{~kg}$ compared to $6.8 \mathrm{~kg}$ in patients receiving no weight-loss medication (values 1 year after BIB removal, $P<0.001)$.

\section{Specific Aspects of BIB Therapy}

Nonrandomized studies have yielded interesting information in various aspects:

\section{Weight Loss According to BMI Categories}

Six months after BIB insertion, the absolute weight loss tends to be higher in patients with BMI higher vs lower than $40 \mathrm{~kg} / \mathrm{m}^{2}$ (mean, $22.5 \mathrm{vs} 12.5 \mathrm{~kg}$ ) [29]. However, when the percentage of excess weight loss was considered, it was significantly higher in patients of lower compared to higher BMI categories, and it even attained a median of $97 \%$ in women with a baseline BMI comprised between 25 and $30 \mathrm{~kg} / \mathrm{m}^{2}$ (Fig. 2).

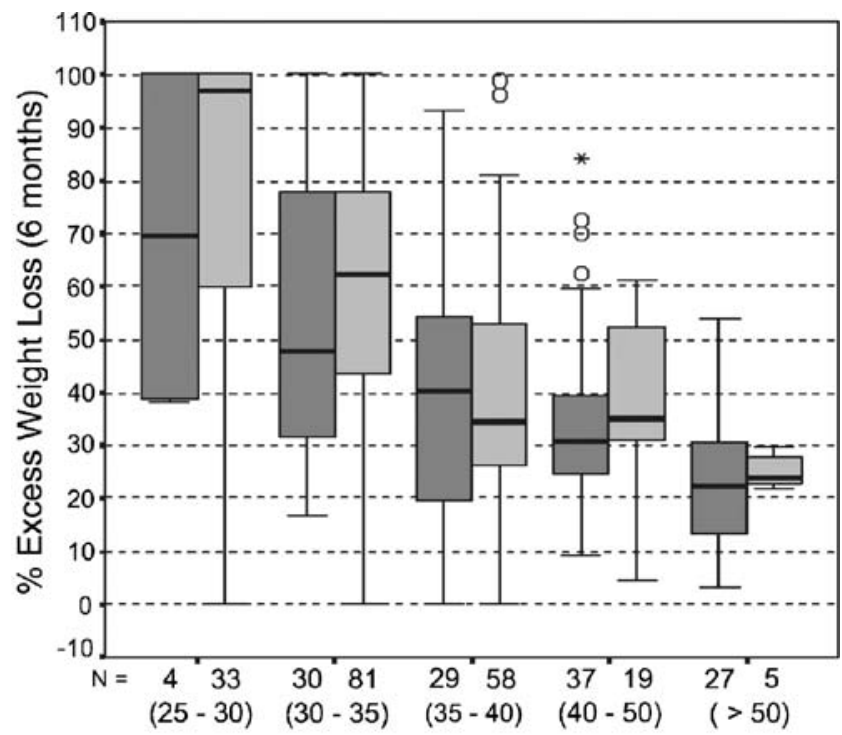

Gender

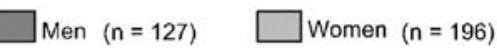

Fig. 2 Boxplot showing the percentage of excess weight loss 6 months after insertion of the Bioenterics intragastric balloon in 323 patients. Numbers $(N)$ of men and women are indicated separately for each category of BMI (figures between parentheses below the $X$ axis). Adapted from Genco et al. [19] with permission 


\section{Comorbidities and Quality of Life}

A large retrospective study from the Italian group for LapBand has shown that, although modest, weight losses induced by the BIB allowed resolving or improving most comorbidities associated with obesity, in particular, respiratory disorders, hypertension, diabetes, and osteoarthropathy (Table 2) [18]. Unfortunately, no study has assessed the evolution of comorbidities during follow-up after BIB removal or potential changes in mortality after BIB treatment. The effect of BIB therapy on obstructive sleep apnea has been specifically studied because it poses significant challenges to anesthesiologists during the perioperative period. BIB therapy in 17 obese men affected with this syndrome (mean BMI, $55.8 \mathrm{~kg} / \mathrm{m}^{2}$ ) induced a nearly complete resolution, and this was associated with an increase in the pharyngeal cross-sectional area [8]. No treatment failure was observed in patients who lost $>12 \%$ body weight.

The impact of intragastric balloon therapy on the quality of life was assessed using a validated tool in a single small study that used an air-filled balloon: the authors reported a significant improvement of the quality of life up to 1 month after BIB removal (Fig. 3) [33]. Again, no follow-up data were provided.

\section{Use of the BIB in Specific Patient Populations}

Binge eaters represent $16-30 \%$ of obese patients involved in weight loss programs. This disorder is usually diagnosed following an interview with a psychologist and fulfillment of self-assessment questionnaires based on established criteria. It might be a valuable predictor of poor results with the BIB, as binge eaters were reported to request early BIB removal more frequently than nonbinge eaters and,

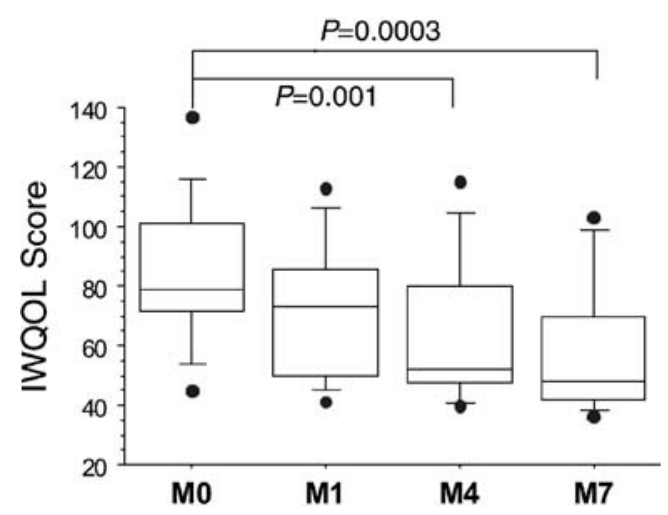

Fig. 3 Evolution of the quality of life as assessed by the IWQOL-Lite score in 17 patients (mean BMI, $34.4 \mathrm{~kg} / \mathrm{m}^{2}$ ) treated with the Bioenterics intragastric balloon (lower scores indicate better quality of life). M0: baseline; $M 1$ and $M 4,1$ and 4 months after balloon insertion, respectively; $M 7,1$ month after balloon removal. Reproduced with permission from Mion et al. [25]

finally, to experience lower BMI losses $\left(3.3 \mathrm{vs} 5.7 \mathrm{~kg} / \mathrm{m}^{2}\right.$, $P<0.05)$ [26].

Superobese $\left(\mathrm{BMI}>50 \mathrm{~kg} / \mathrm{m}^{2}\right.$ ) patients frequently fail to achieve adequate weight loss after bariatric surgery and they harbor an increased surgical risk compared to less severely obese patients, so that preoperative weight loss has been recommended. Three groups of authors have reported grossly concordant results with preoperative BIB therapy: approximately $90 \%$ of patients (mean BMI, $58-64 \mathrm{~kg} / \mathrm{m}^{2}$ ) tolerated the BIB, and they lost between $10 \%$ and $26 \%$ of excess weight $[6,9,34]$. In the study that included controls [9], preoperative BIB therapy was associated with a lower rate of conversion to open surgery ( $0 \%$ vs $16 \%)$, shorter operative time, and shorter postoperative hospital stay (all $P$ values $<0.05$ ). However, (1) the evolution of weight during follow-up after surgery was not significantly different in patients with or without BIB preparation and

Table 2 Comorbidities at the time of BIB removal (6 months) in a nationwide series of 2,515 patients (mean BMI, $44.4 \pm 7.8 \mathrm{~kg} / \mathrm{m}^{2}$ ) treated with the Bioenterics intragastric balloon

\begin{tabular}{|c|c|c|c|c|}
\hline \multirow[t]{2}{*}{ Comorbidity } & \multicolumn{2}{|l|}{ Resolution } & \multirow[t]{2}{*}{ Improvement $^{\mathrm{a}}(\%)$} & \multirow[t]{2}{*}{ No change $(\%)$} \\
\hline & Criteria & Incidence $(\%)$ & & \\
\hline Hypertension $(n=509)$ & Systolic $<120-130 \mathrm{mmHg}$ & 44.8 & 48.9 & 6.3 \\
\hline Diabetes $(n=488)$ & 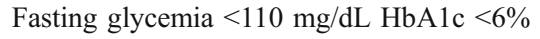 & 32.8 & 54.4 & 13.1 \\
\hline Respiratory disorders $(n=247)$ & Absence of symptoms & 83.0 & 17.0 & 0 \\
\hline Osteoarthropathy $(n=271)$ & Absence of pain & 40.9 & 46.1 & 12.9 \\
\hline Dyslipidemia $(n=318)$ & Triglycerides $<200 \mathrm{mg} / \mathrm{dL}$ & 15.4 & 36.5 & 48.1 \\
\hline Others $(n=176)$ & & 71.6 & 8.5 & 19.8 \\
\hline
\end{tabular}

${ }^{\text {a }}$ Improvement was defined as lower drug dosage or shift to other therapy, excepted for the improvement of respiratory disorders defined as the disappearance of obstructive sleep apnea syndrome with persisting tachypnea after physical activity, and that of dyslipidemia, which was prevalently linked to normalization of tryglicerides while modification of cholesterolemia was less important. Adapted from Genco et al. [18]. 
(2) patients should be clearly informed that BIB therapy is not a replacement for bariatric surgery (weight regain after BIB removal may be very rapid and important in superobese patients) [7]. The main effect of BIB therapy (apart from the improvement of obstructive sleep apnea) could be a reduction in liver volume that is much more important than that of body weight (a voluminous left hepatic lobe may impede laparoscopic approach to the stomach) [15].

Adolescents have been included in many studies investigating the BIB, but their outcome has rarely been reported separately from that of other patients. In a large series [29], mean BMI decrease with the BIB was similar in 21 adolescents compared to 302 adults $\left(5.0 \mathrm{vs} 5.3 \mathrm{~kg} / \mathrm{m}^{2}\right.$, respectively), and no significant weight change occurred in the five adolescents who were followed during 1 year after BIB removal.

\section{BIB-filling Volume}

According to the manufacturer, the BIB may be filled with 400 to $700 \mathrm{ml}$ of saline $(500$ to $600 \mathrm{ml}$ is used in most studies). A nonrandomized retrospective study has suggested that a $600-\mathrm{ml}$ filling volume could provide a higher weight loss at the time of BIB removal compared to that obtained with a 500-ml filling volume (12.9 vs $8.6 \mathrm{~kg}$, $P<0.002$ ) [27]. However, this result should be confirmed since criteria for choosing the filling volume (e.g., body height) were not stated, and the incidence of side effects was not detailed according to filling volumes.

\section{BIB for Selecting Among Bariatric Procedures}

The "BIB test" has been proposed to predict in a particular patient if a gastric restrictive surgical procedure would be successful [21]. This test has been prospectively evaluated in 40 patients (mean BMI, $46.5 \mathrm{~kg} / \mathrm{m}^{2}$ ) who underwent BIB therapy followed by laparoscopic adjustable gastric banding [11]. Successful treatments were defined as $\geq 10 \%$ baseline weight loss with the BIB, and a further weight loss of $\geq 15 \%$ with surgery. This study found that the "BIB test" had mixed predictive values for further weight loss with banding (positive and negative predictive values; 56\% and $73 \%$, respectively), but the final weight loss was higher in patients with successful vs unsuccessful BIB therapy (12.4 vs $9.0 \mathrm{~kg} / \mathrm{m}^{2}$ at 18 months, respectively; $P=0.03$ ).

\section{BIB as a First Step Toward Bariatric Surgery}

BIB therapy has been suggested to facilitate the acceptance of bariatric surgery: among 140 patients who had initially refused bariatric surgery but had agreed for BIB therapy, $32 \%$ had undergone bariatric surgery at a mean follow-up of 18 months [24]. Bariatric surgery was most frequent (64\%) among patients who had successfully lost weight with the BIB (and, hence, had experienced associated benefits) but who had then regained weight, while it was mixed (33\%) in those who had not significantly lost weight, and very low $(7 \%)$ in those who had maintained a successful weight loss during follow up.

\section{Complications}

Reporting of complications was extremely variable between studies; severe complications could be analyzed in 20 studies, totaling 4,240 patients $[5,8-10,12-15,17-21,23$, 25-27, 29-31, 34]. Three deaths were reported (treatmentrelated death rate, $0.07 \%$ ), due to gastric perforation in patients with previous Nissen fundoplication $(n=2)$ and bronchoaspiration following BIB insertion $(n=1)$. Gastric perforation was reported in a total of nine patients $(0.21 \%)$ (five of them had a previous history of gastric surgery). Bowel obstruction required surgical, endoscopic, or combined BIB removal in seven $(0.17 \%)$ patients. Early endoscopic BIB removal (mainly for digestive intolerance) was reported in $103(2.43 \%)$ patients and hypokalemia in $20(0.47 \%)$ patients.

Reporting of less severe complications was less consistent among studies, probably because these can usually be managed by phone calls or during scheduled visits. Abdominal pain after the first week following BIB insertion has been reported in $0-15.9 \%$ of cases $[5,27]$. Spontaneous BIB deflation has been reported in extremely varying proportions of cases (3-23\%) in different studies [12, 20, $21]$, likely due to the practice in some centers of maintaining balloons in place beyond the 6-month recommended period. Spontaneous BIB deflation may be detected by repeated ultrasonography at fixed time intervals (although a learning curve does exist for this technique and its cost-effectiveness is not established) [14], green coloration of the urines (methylene blue present in the BIB is absorbed and excreted by the kidneys in case of leakage), or a sudden change of patient's tolerance to food intake. Most deflated balloons were spontaneously eliminated, but particular attention should be paid in patients at increased risk for bowel obstruction (e.g., previous history of abdominal surgery). Gastroduodenal ulcers (often asymptomatic) were reported in $0.4 \%$ of patients. Esophagitis has been specifically analyzed by Rossi et al. in 121 patients: esophagitis was present at the time of BIB insertion in $15 \%$ of patients, and its incidence and severity were slightly increased (up to $18.2 \%$ ) with the BIB, even if proton pump inhibitors were prescribed "on-demand" [28]. 


\section{Conclusion}

The BIB was found to be effective for promoting short-term weight loss in about two thirds of patients and safe provided that contraindications were observed. Mean weight loss was $17.8 \mathrm{~kg}$, with higher absolute values observed in higher BMI categories. BIB therapy was followed by a significant improvement in comorbidities at short term. Patients with a BMI comprised between 30.0 and $39.9 \mathrm{~kg} / \mathrm{m}^{2}$ who have failed to lose weight with other approaches represented the best candidates for BIB therapy, as well as superobese patients in preparation for bariatric surgery. Although the BIB has been available for $>10$ years, data are still lacking about the success of weight maintenance $\geq 2$ years after BIB removal and about predictive factors for short- and long-term success. Improvements are still awaited, in particular to soften early digestive intolerance (this is a significant obstacle to ambulatory BIB insertion in many centers) and to optimize balloon-filling volume/treatment duration.

\section{References}

1. Schapiro M, Benjamin S, Blackburn G, et al. Obesity and the gastric balloon: a comprehensive workshop. Tarpon Springs, Florida, March 19-21, 1987. Gastrointest Endosc. 1987;33:323-7.

2. Forestieri P, De Palma GD, Formato A, et al. Heliosphere bag in the treatment of severe obesity: preliminary experience. Obes Surg. 2006;16:635-7.

3. Mion F, Gincul R, Roman S, et al. Tolerance and efficacy of an air-filled balloon in non-morbidly obese patients: results of a prospective multicenter study. Obes Surg. 2007;17:764-9.

4. Gaggiotti G, Tack J, Garrido AB, Palau M, Cappelluti G, Di Matteo F. Adjustable totally implantable intragastric prosthesis (ATIIP)-Endogast for treatment of morbid obesity: one-year follow-up of a multicenter prospective clinical survey. Obes Surg. 2007; 17:949-56.

5. Al-Momen A, El-Mogy I. Intragastric balloon for obesity: a retrospective evaluation of tolerance and efficacy. Obes Surg. 2005; 15:101-5.

6. Alfalah H, Philippe B, Ghazal F, et al. Intragastric balloon for preoperative weight reduction in candidates for laparoscopic gastric bypass with massive obesity. Obes Surg. 2006;16:147-50.

7. Angrisani L, Lorenzo M, Borrelli V, Giuffre M, Fonderico C, Capece G. Is bariatric surgery necessary after intragastric balloon treatment? Obes Surg. 2006;16:1135-7.

8. Busetto L, Enzi G, Inelmen EM, et al. Obstructive sleep apnea syndrome in morbid obesity: effects of intragastric balloon. Chest. 2005;128:618-23.

9. Busetto L, Segato G, De Luca M, et al. Preoperative weight loss by intragastric balloon in super-obese patients treated with laparoscopic gastric banding: a case-control study. Obes Surg. 2004;14:671-6.

10. Carbonelli MG, Fusco MA, Cannistrà F, Andreoli A, De Lorenzo A. Body composition modification in obese patients treated with intragastric balloon. Acta Diabetol. 2003;40 Suppl 1:S261-2.

11. de Goederen-van der Meij S, Pierik RG, Oudkerk Pool M, Gouma DJ, Mathus-Vliegen LM. Six months of balloon treatment does not predict the success of gastric banding. Obes Surg. 2007;17: 88-94.

12. Doldi SB, Micheletto G, Perrini MN, Rapetti R. Intragastric balloon: another option for treatment of obesity and morbid obesity. Hepato-gastroenterology. 2004;51:294-7.

13. Evans JD, Scott MH. Intragastric balloon in the treatment of patients with morbid obesity. Br J Surg. 2001;88:1245-8.

14. Francica G, Giardiello C, Iodice G, et al. Ultrasound as the imaging method of choice for monitoring the intragastric balloon in obese patients: normal findings, pitfalls and diagnosis of complications. Obes Surg. 2004;14:833-7.

15. Frutos MD, Morales MD, Lujan J, Hernandez Q, Valero G, Parrilla P. Intragastric balloon reduces liver volume in super-obese patients, facilitating subsequent laparoscopic gastric bypass. Obes Surg. 2007;17:150-4.

16. Galloro G, Sivero L, Magno L, et al. New technique for endoscopic removal of intragastric balloon placed for treatment of morbid obesity. Obes Surg. 2007;17:658-62.

17. Ganesh R, Rao AD, Baladas HG, Leese T. The Bioenteric Intragastric Balloon (BIB) as a treatment for obesity: poor results in Asian patients. Singapore Med J. 2007;48:227-31.

18. Genco A, Bruni T, Doldi SB, et al. Bioenterics intragastric balloon: the Italian experience with 2,515 patients. Obes Surg. 2005; $15: 1161-4$.

19. Genco A, Cipriano M, Bacci V, et al. BioEnterics Intragastric Balloon (BIB): a short-term, double-blind, randomised, controlled, crossover study on weight reduction in morbidly obese patients. Int J Obes. 2006;30:129-33.

20. Herve J, Wahlen CH, Schaeken A, et al. What becomes of patients one year after the intragastric balloon has been removed? Obes Surg. 2005;15:864-70.

21. Loffredo A, Cappuccio M, De Luca M, et al. Three years experience with the new intragastric balloon, and a preoperative test for success with restrictive surgery. Obes Surg. 2001;11: $330-3$.

22. Martinez-Brocca MA, Belda $\mathrm{O}$, Parejo $\mathrm{J}$, et al. Intragastric balloon-induced satiety is not mediated by modification in fasting or postprandial plasma ghrelin levels in morbid obesity. Obes Surg. 2007;17:649-57.

23. Mathus-Vliegen EM, Tytgat GN. Intragastric balloon for treatment-resistant obesity: safety, tolerance, and efficacy of 1-year balloon treatment followed by a 1-year balloon-free follow-up. Gastrointest Endosc. 2005;61:19-27.

24. Melissas J, Mouzas J, Filis D, et al. The intragastric balloonsmoothing the path to bariatric surgery. Obes Surg. 2006;16: 897-902.

25. Mion F, Napoleon B, Roman S, et al. Effects of intragastric balloon on gastric emptying and plasma ghrelin levels in nonmorbid obese patients. Obes Surg. 2005;15:510-6.

26. Puglisi F, Antonucci N, Capuano P, et al. Intragastric balloon and binge eating. Obes Surg. 2007;17:504-9.

27. Roman S, Napoleon B, Mion F, et al. Intragastric balloon for "non-morbid" obesity: a retrospective evaluation of tolerance and efficacy. Obes Surg. 2004;14:539-44.

28. Rossi A, Bersani G, Ricci G, Petrini C, Defabritiis G, Alvisi V. Intragastric balloon insertion increases the frequency of erosive esophagitis in obese patients. Obes Surg. 2007;17:1346-9.

29. Sallet JA, Marchesini JB, Paiva DS, et al. Brazilian multicenter study of the intragastric balloon. Obes Surg. 2004;14:991-8.

30. Spyropoulos C, Katsakoulis E, Mead N, Vagenas K, Kalfarentzos F. Intragastric balloon for high-risk super-obese patients: a prospective analysis of efficacy. Surg Obes Relat Dis. 2007;3:78-83.

31. Totté E, Hendrickx L, Pauwels M, Van Hee R. Weight reduction by means of intragastric device: experience with The BioEnterics Intragastric Balloon. Obes Surg. 2001;11:519-23. 
32. Van Hee R, Van Wiemeersch S, Lasters B, Weyler J. Use of antiemetics after intragastric balloon placement: experience with three different drug treatments. Obes Surg. 2003;13:932-7.

33. Wahlen $\mathrm{CH}$, Bastens $\mathrm{B}$, Herve $\mathrm{J}$, et al. The BioEnterics Intragastric Balloon (BIB): how to use it. Obes Surg. 2001;11:524-7.

34. Weiner R, Gutberlet H, Bockhorn H. Preparation of extremely obese patients for laparoscopic gastric banding by gastric-balloon therapy. Obes Surg. 1999;9:261-4.
35. National Institutes of Health. Clinical guidelines on the identification, evaluation, and treatment of overweight and obesity in adults. The evidence report. National Institutes of Health. 1998;6 Suppl 2:51S-209S.

36. Machytka E, Klvana P, Hanuskova L, Janik I. Use of pharmacotherapy for long-term maintenance of weight loss following explantation of intragastric balloon (BIB). Gut. 2007;57: A290. 